\title{
Robotic Retroauricular Thyroidectomy
}

\author{
Muhammet Recai Mazlumoglu* \\ Otorhinolaryngology clinic, hinis sehit yavuz yurekseven state hospital, erzurum, Turkey
}

Received: October 24, 2017; Accepted: October 31, 2017; Published: November 15, 2017

*Corresponding author: Muhammet Recai Mazlumoglu, MD Otorhinolaryngology Clinic, Hinis Sehit Yavuz Yurekseven State Hospital, 25100, Erzurum, Turkey, Tel: +90 542435 5835; Fax: +90 0442327 3632; E-mail: dr.mazlumoglu@gmail.com

\section{Abstract}

Patient complaints regarding cosmetic outcomes of conventional thyroid surgery have encouraged continuous innovations in surgical techniques, and incision size has been progressively reduced through the development and use of auxiliary devices. Endoscopic methods can significantly reduce the size of neck region incisions, and local incisions can be eliminated completely by accessing the region endoscopically via axillary, oral, and retroauricular approaches. Use of the da Vinci robotic system for head and neck surgery has further improved cosmetic outcomes. Here publications are reviewed related to Robotic Retroauricular Thyroidectomy (RRT) and evaluate the applications, advantages, and disadvantages of the method.
\end{abstract}

Keywords: Robot; Surgery; Thyroid; Retroauricular

\section{Introduction}

Surgery is the gold standard treatment for thyroid cancer and suspicious thyroid nodules [1]. Conventional open surgical techniques have been replaced in recent years, initially by minimally invasive video-assisted procedures, and more recently by the da Vinci robotic surgical system (Intuitive Surgical, Sunnyvale, CA, USA) [2]. Robotic surgical techniques have advanced particularly rapidly in countries such as South Korea, Japan, and China, where there is considerable cultural pressure to reduce the scarring associated with head and neck surgery. This includes the development of novel Transaxillary, Transoral, and Retroauricular techniques [3,4]. Terris et al. first described Robotic Retroauricular Thyroidectomy (RRT) in 2011, as 'robotic facelift thyroidectomy' [5]. Later cadaver study case series and original articles were reported in the literature [6-14].

\section{Patient Selection}

Careful patient selection is important to increase the success rate of RRT; suboptimal patient selection can result in harm. Typically, the ideal patient for RRT would have some or all of the following characteristics: a body mass index (BMI) $<40$; no previous neck surgery or irradiation; high cosmetic expectations; and a history of keloid or hypertrophic scar formation. RRT is not appropriate in patients with Graves' disease, nodules with a diameter $>4 \mathrm{~cm}$, or substernal or retropharyngeal goiters.
Regarding thyroid neoplasia, RRT should be used in cases where there is differentiated thyroid cancer and no pathologic lymphadenopathy or invasion into the surrounding tissues [1]. In this review of the literature, RRT was primarily performed in female patients who were concerned about scarring.

Although RRT is generally recommended for thyroid lobectomies, both Byeon et al. and Kim et al. successfully performed total thyroidectomies, with or without neck dissection, using this technique[10,11]. They considered advanced lymph node metastases with extracapsular spread, and advanced thyroid cancer that invaded the surrounding tissues, as contraindications for the use of RRT. They did not consider lymph node metastases without extracapsular spread to be a contraindication. In general, patients with vocal cord paralysis were deemed ineligible for RRT, which was applied most frequently in patients with suspicious nodules or papillary thyroid carcinoma.

\section{Operative Technique}

The patient is positioned supine with the head rotated 30 degrees toward the side contralateral to the incision site. The arms are placed at the patient's sides. A $1 \mathrm{~cm}$ region on the occiput should be shaved and routine use of laryngeal nerve monitoring is recommended [5].

A postauricular incision is made adjacent to the ear lobe and extended upward in the direction of the occipital hair line. A musculocutaneous flap is enlarged deep to the platysma and superficial to the external jugular vein and great auricular nerve. The flap is advanced through the ventral aspect of the sternocleidomastoid muscle until reaching the clavicle. At this stage, a triangular area formed by the omohyoid, sternocleidomastoid, and sternohyoid muscles is delineated. The omohyoid and sternohyoid muscles are retracted anteriorly, and the sternocleidomastoid is retracted posteriorly. This allows for direct visualization of the thyroid gland. The retractors are fixed in place to provide a stable field of vision [1,5]. Although in most cases the flap is extended deep to the platysma, some surgeons prefer a superficial approach, in an attempt to reduce the risk of 
damaging the internal jugular vein or the great auricular nerve $[12,13]$.

The da Vinci Si or Xi system (Intuitive Surgical) is then docked and the thyroid is excised using a 30-degree dualchannel endoscope and a harmonic scalpel. Excision begins from the upper pole of the thyroid and care is taken to protect the parathyroid glands. The thyroid gland itself is retracted ventrally throughout. The recurrent laryngeal nerve is identified within the tracheoesophageal groove. Finally, the relevant lobe of the thyroid is removed from the trachea by cutting the isthmus $[3,5]$.

In patients undergoing total thyroidectomy, the next step was first described by Byeon et al. and proceeds as follows [10]. The Maryland dissecting forceps (Intuitive Surgical) are replaced by prograsp forceps (Intuitive Surgical) and passed toward the contralateral thyroid lobe. The upper pole is dissected away, beginning at the point of the preceding isthmusectomy. After the upper pole is released, the specimen is dissected from the medial to lateral aspect. At this stage, recurrent laryngeal nerve can be readily identified within the tracheoesophageal groove. The contralateral lymph nodes may also be dissected. Care must be taken to control bleeding once the entire specimen has been removed. The operation concludes with the placement of a drain [10].

In many cases patients are discharged on the same day as the RRT procedure. However, this may vary according to local policy or surgeon preference. Byeon et al. discharged patients after an average of 6 days; the discharge time varied depending on the type of robotic-assisted surgery performed. Alshehri et al. found that a single day of observation was generally sufficient $[10,14]$.

The complications of RRT are similar to those of open surgical techniques and include infection, seroma, hematoma, recurrent laryngeal nerve injury, and hypoparathyroidism. The

Table 1: Advantages and disadvantages of Robotic Retroauricular Thyroidectomy

\begin{tabular}{|c|c|}
\hline Advantages & Disadvantages \\
\hline Cosmetic & High expense \\
\hline $\begin{array}{c}\text { Imaging advantage (three- } \\
\text { dimensional imaging) }\end{array}$ & Long operating times \\
\hline Lack of tremor & Lack of tactile feedback \\
\hline $\begin{array}{c}\text { Manipulation in a small work } \\
\text { area }\end{array}$ & $\begin{array}{c}\text { Requirement for experienced } \\
\text { surgeons }\end{array}$ \\
\hline $\begin{array}{c}\text { Reduced field of dissection(faster } \\
\text { recovery and decreased } \\
\text { postoperative discomfort) }\end{array}$ & $\begin{array}{c}\text { Suitability only for a select group } \\
\text { of patients }\end{array}$ \\
\hline $\begin{array}{c}\text { Reduced risk of injury to the } \\
\text { great vessels and sensory nerves }\end{array}$ & $\begin{array}{c}\text { Injury to greater auricular and } \\
\text { marginal mandibular nerves }\end{array}$ \\
\hline
\end{tabular}

retroauricular approach has the additional complication of possible flap or greater auricular nerve damage. No significant intraoperative complications have been reported in the published literature. Studies including large number of patients that directly compare the complication rates of open and closed surgical techniques are lacking $[1,10,14]$. Alshehri et al. compared RRT with non-robotic methods and found that RRT significantly reduced both the duration of surgery and intraoperative blood loss [14].

RRT has several disadvantages including high expense, long operating times, the requirement for experienced surgeons, and suitability only for a select group of patients. However, RRT has several advantages [Table 1].

As a result; in RRT can be safely used in patients with high cosmetic expectations. There remains a need for large case studies comparing conventional open surgical techniques to RRT.

\section{References}

1. Alabbas H, Bu Ali D, Kandil E. Robotic retroauricular thyroid surgery. Gland Surg. 2016; 5(6):603-606; Doi: 10.21037/gs.2016.12.06

2. Lira RB, Chulam TC, Kowalski LP. Safe implementation of retroauricular robotic and endoscopic neck surgery in South America. Gland Surg. 2017; 6(3): 258-266; Doi: 10.21037/ gs.2017.03.17

3. Thankappan K, Dabas S, Deshpande M. Robotic retroauricular thyroidectomy: initial experience from India. Gland Surg. 2017; 6(3): 267-271; Doi: 10.21037/ gs.2017.03.02

4. Chang EH, Kim HY, Koh YW, Chung WY. Overview of robotic thyroidectomy. Gland Surg. 2017; 6(3): 218-228; Doi: 10.21037/ gs.2017.03.18

5. Terris DJ, Singer MC, Seybt MW. Robotic Facelift Thyroidectomy: II. Clinical Feasibility and Safety. Laryngoscope. 2011; 121(8):16361641; Doi: 10.1002/lary.21832

6. Sharma A, Albergotti WG, Duvvuri U. Applications of Evolving Robotic Technology for Head and Neck Surgery. Ann Otol Rhinol Laryngol. 2016; 125(3):207-212; Doi: 10.1177/0003489415606448

7. Byeon HK, Ban MJ, Lee JM, Ha JG, Kim ES, YW Koh, Choi EC. RobotAssisted Sistrunk's Operation, Total Thyroidectomy, and Neck Dissection via a Transaxillary and Retroauricular (TARA) Approach in Papillary Carcinoma Arising in Thyroglossal Duct Cyst and Thyroid Gland. Ann Surg Oncol. 2012; 19(13):4259-4261; Doi: 10.1245/s10434-012-2674-y

8. Mohamed SE, Saeed A, Moulthrop T, Kandil E. Retroauricular Robotic Thyroidectomy with Concomitant Neck-Lift Surgery. Ann Surg Oncol. 2015; 22(1):172; Doi: 10.1245/s10434-013-3470-z

9. Byeon HK, Holsinger FC, Tufano RP, Chung HJ, Kim WS, Koh YW, et al, Robotic Total Thyroidectomy with Modified Radical Neck Dissection via Unilateral Retroauricular Approach. Ann Surg Oncol. 2014; 21(12):3872-3875; Doi: 10.1245/s10434-014-3896-y

10. Byeon HK, Kim DH, Chang JW, Ban MJ, Park JH, Kim WS, et al. Comprehensive Application of Robotic Retroauricular Thyroidectomy: The Evolution of Robotic Thyroidectomy. Laryngoscope. 2016; 126(8): 1952-1957; Doi: 10.1002/lary.25763
Page 2 of 3 
11. Kim WS, Koh YW, Byeon HK, Park YM, Chung HJ, Kim ES, et al. RobotAssisted Neck Dissection via a Transaxillary and Retroauricular Approach Versus a Conventional Transcervical Approach in Papillary Thyroid Cancer with Cervical Lymph Node Metastases. J laparoendoscadv Surg Tech A. 2014; 24(6): 367-372; Doi: 10.1089/ lap.2013.0296.

12. Saeed A, Alsaleh N, Moulthrop T, MD, Aslam R, DO, Kandil E. Modified Approach for Robotic Retroauricular Thyroidectomy: Preclinical Simulation and a Surgical Case. Surg Innov. 2015; 22(6): 577-581; Doi: $10.1177 / 1553350614556361$
13. Kandil E, Saeed A, Mohamed SE, Alsaleh N, Aslam R, Moulthrop T. Modified robotic-assisted thyroidectomy: an initial experience with the retroauricular approach. Laryngoscope. 2015; 125(3): 767-771; Doi: 10.1002/lary.24786

14. Alshehri M, Mohamed HE, Moulthrop T, Kandil E. Robotic thyroidectomy and parathyroidectomy: An initial experience with retroauricular approach. Head Neck. 2017; 39(8):1568-1572; Doi: 10.1002/hed.24794 